\title{
A systematic review of lenvatinib and sorafenib for treating progressive, locally advanced or metastatic, differentiated thyroid cancer after treatment with radioactive iodine
}

\author{
Nigel Fleeman ${ }^{1 *}$ (D), Rachel Houten ${ }^{1}$ (D), Marty Chaplin ${ }^{1}$ (D), Sophie Beale ${ }^{1}$ (D), Angela Boland ${ }^{1}$ (D), Yenal Dundar ${ }^{1}$ (D),
} Janette Greenhalgh ${ }^{1}$ (D) Rui Duarte ${ }^{1}$ (D) and Aditya Shenoy ${ }^{2}$ (D)

\begin{abstract}
Background: Treatment with radioactive iodine is effective for many patients with progressive, locally advanced or metastatic, differentiated thyroid cancer. However, some patients become refractory to treatment. These types of patients are considered to have radioactive iodine refractory differentiated thyroid cancer (RR-DTC).

Methods: We searched Embase, MEDLINE, PubMed and the Cochrane Library from January 1999 through January 2017. Reference lists of included studies and ongoing trial registries were also searched. Reports of randomized controlled trials (RCTs), prospective observational studies, and systematic reviews/indirect comparisons were eligible for inclusion. In the absence of direct clinical trial evidence comparing lenvatinib versus sorafenib, we assessed the feasibility of conducting an indirect comparison to obtain estimates of the relative efficacy and safety of these two treatments.
\end{abstract}

Results: Of 2364 citations, in total, 93 papers reporting on 2 RCTs (primary evidence), 9 observational studies and 13 evidence reviews (supporting evidence) were identified. Compared to placebo, RCT evidence demonstrated improvements with lenvatinib or sorafenib in median progression-free survival (PFS) and objective tumour response rate (ORR). Overall survival (OS) was confounded by high treatment crossover $(\geq 75 \%)$ in both trials. Adverse events (AEs) were more common with lenvatinib or sorafenib than with placebo but the most common AEs associated with each drug differed. Primarily due to differences in the survival risk profiles of patients in the placebo arms of the RCTs, we considered it inappropriate to indirectly compare the effectiveness of lenvatinib versus sorafenib. ORR and $A E$ findings for lenvatinib and sorafenib from the supporting evidence were broadly in line with RCT evidence. Health-related quality of life (HRQoL) data were limited.

Conclusions: Lenvatinib and sorafenib are more efficacious than placebo (a proxy for best supportive care) for treating RR-DTC. Uncertainty surrounds the extent of the impact on OS and HRQoL. Lenvatinib could not reliably be compared with sorafenib. Choice of treatment is therefore likely to depend on an individual patient's circumstances.

Keywords: Thyroid cancer, Systematic review, Clinical effectiveness, Lenvatinib, Sorafenib, Tyrosine kinase inhibitor

\footnotetext{
* Correspondence: nigel.fleeman@liverpool.ac.uk; https://www.liv.ac.uk/lrig

1 Liverpool Reviews \& Implementation Group (LRiG), Department of Health

Services Research, Institute of Population Health Sciences, University of

Liverpool, Whelan Building, Liverpool L69 3GB, UK

Full list of author information is available at the end of the article
}

(c) The Author(s). 2019 Open Access This article is distributed under the terms of the Creative Commons Attribution 4.0 International License (http://creativecommons.org/licenses/by/4.0/), which permits unrestricted use, distribution, and

reproduction in any medium, provided you give appropriate credit to the original author(s) and the source, provide a link to the Creative Commons license, and indicate if changes were made. The Creative Commons Public Domain Dedication waiver (http://creativecommons.org/publicdomain/zero/1.0/) applies to the data made available in this article, unless otherwise stated. 


\section{Background}

Thyroid cancer accounts for approximately 1\% of all new malignancies in the United Kingdom (UK) [1] and approximately $3 \%$ of all new malignancies in the United States (US) [2]. Commonly asymptomatic and so often discovered incidentally [3], the most common type of thyroid cancer is differentiated thyroid cancer (DTC). A review of 2936 US patients registered with DTC found papillary carcinoma (PTC), follicular carcinoma (FTC) and Hürthle cell carcinoma to constitute 86,10 and $4 \%$ of cases respectively [4]. Globally, DTC incidence is increasing [5]. In part, this increase has been attributed to improved diagnostic and detection techniques [6].

Surgery followed by daily oral medication (levothyroxine) to suppress blood thyroid stimulating hormone (TSH) levels is the mainstay of treatment for DTC [7-10]. Additional treatment in the form of radioactive iodine may be required for patients who develop local, regional or metastatic disease (5 to $20 \%$ patients $[7,9]$ ). For most patients, radioactive iodine treatment is effective. However, 5 to $15 \%[4,11-15]$ of people with DTC develop radioactive iodine refractory differentiated thyroid cancer (RR-DTC), i.e. they are unable to safely tolerate treatment or they develop DTC that has become resistant to treatment.

For patients with RR-DTC, treatment options have been limited. Chemotherapy is rarely or never recommended by the authors of clinical guidelines [7-10] and thus, for many patients, best supportive care (BSC) has been the only treatment option. However, the authors of published clinical guidelines have noted the promise of targeted therapies including tyrosine kinase inhibitors (TKIs). Lenvatinib is the most recent TKI to be licensed for treating RR-DTC, receiving a licence in the US in February 2015 [16] and in the European Union (EU) in May 2015 [17]. The only other licensed TKI is sorafenib, which was licensed for the treatment of RR-DTC in the US in November 2013 [18] and in the EU in January 2015 [19]. The authors of the US National Comprehensive Cancer Network (NCCN) guidelines now recommend that lenvatinib and sorafenib should be considered for treating progressive and/or symptomatic RR-DTC [10]. The authors, however, caution against their use for patients with stable or slowly progressive indolent disease [10]. The authors of the American Thyroid Association (ATA) guidelines caution that patients who are candidates for TKI therapy "should be thoroughly counseled on the potential risks and benefits of this therapy as well as alternative therapeutic approaches including best supportive care" [7]. Important risks associated with lenvatinib highlighted by regulatory agencies $[16,17]$ include: hypertension; cardiac dysfunction; arterial thromboembolic events; hepatotoxicity, renal failure or impairment; proteinuria; diarrhea; fistula formation and gastrointestinal perforation; QT interval prolongation; hypocalcemia; reversible posterior leukoencephalopathy syndrome; hemorrhagic events; impairment of TSH suppression/thyroid dysfunction; wound healing complications; and embryo-fetal toxicity. Important risks associated with sorafenib highlighted by regulatory agencies $[18,19]$ include: dermatologic toxicities including severe skin adverse events (AEs) and hand-foot syndrome; hypertension; posterior reversible encephalopathy syndrome; hemorrhage (including lung hemorrhage, gastrointestinal hemorrhage and cerebral hemorrhage); arterial thrombosis (myocardial infarction); congestive heart failure; QT interval prolongation; squamous cell cancer of the skin; gastrointestinal perforation; symptomatic pancreatitis and increases in lipase and amylase; hypophosphatemia; renal dysfunction; interstitial lung disease-like events; drug-induced hepatitis; impairment of TSH suppression; and embryo-fetal toxicity.

While lenvatinib and sorafenib are available for treating RR-DTC in several countries, the extent to which they are available to patients has varied. For example, lenvatinib and sorafenib are available for all patients who require these treatments in Scotland via the National Health Service (NHS) [20, 21]. However, prior to August 2018, they were only available for patients in special circumstances in the NHS in England. In order to be routinely used in the NHS in England, a positive recommendation from the National Institute for Health and Care Excellence (NICE) is required. We, the Liverpool Reviews and Implementation Group (LRiG), were commissioned, in our capacity as an independent Assessment Group, to provide an independent review of the clinical and cost effectiveness evidence as part of a NICE multiple technology appraisal (MTA). In this paper, we report our systematic review of the clinical effectiveness evidence for lenvatinib and sorafenib and discuss how the evidence has impacted on NICE recommendations for clinical practice.

\section{Methods}

Our systematic review protocol was registered with PROSPERO, the international prospective register of systematic reviews (registration number CRD42017055516). The review was conducted in accordance with the Centre for Reviews and Dissemination (CRD) published guidance on conducting systematic reviews in healthcare [22] and the review is reported in accordance with the Preferred Reporting Items for Systematic Reviews and Meta-Analyses (PRISMA) guidelines [23].

\section{Search methods for identification of studies}

On 10 January 2017, four electronic databases (Embase (Ovid), MEDLINE (Ovid), PubMed and the Cochrane Library) were searched for studies published since 1 
January 1999. On 16 May 2017, the clinicaltrials.gov website (a service of the US National Institutes of Health), the International Clinical Trials Registry Platform and the European Union Clinical Trials Register, were searched for information on studies in progress. To identify relevant studies, a combination of index terms for the disease (e.g. thyroid neoplasms) and free text words (e.g. lenvatinib or Lenvima or E7080 or Sorafenib or Nexavar or bay439006) were employed. The database searches were limited to human research and English language studies. No other search restrictions were applied. The search strategies employed are provided in Additional file 1: Online Resource 1.

Evidence submissions from the sponsors of lenvatinib [24] and sorafenib [25] that were submitted to NICE as part of the MTA process were considered for inclusion in our review. The lists of references from the company submissions and all relevant studies identified via the literature searches were cross-checked to identify any papers not identified by the electronic searches.

\section{Study selection and data extraction}

Randomized controlled trials (RCTs), prospective observational studies and systematic reviews/indirect comparisons (hereafter referred to as evidence reviews) of lenvatinib or sorafenib were selected for inclusion in the review. To be included, the population must have included adults with progressive, locally advanced or metastatic thyroid cancer refractory to radioactive iodine, of which at least a subgroup of patients had RR-DTC. A summary of the a priori inclusion and exclusion criteria are provided in Table 1.

Two reviewers independently screened all titles and abstracts (screening stage 1). Full-text articles of all potentially relevant citations identified during screening stage 1 were retrieved and assessed for eligibility based on the inclusion criteria (screening stage 2). Where necessary, any discrepancies or uncertainties were resolved by discussion or consultation with a third reviewer.

Two reviewers independently extracted and checked data by using a pre-tested data extraction form. Data were extracted relating to study design, patient characteristics and outcomes for RCTs and observational studies and the number and type of studies included, type of analysis conducted and the overall findings/conclusions for evidence reviews. For all study types, data reported in multiple publications were extracted and reported as a single study.

\section{Quality assessment}

The quality of included RCTs and evidence reviews was assessed according to the criteria set out in the Centre for Review and Dissemination's Guidance [22] for undertaking reviews in healthcare. Two reviewers independently assessed the quality of these studies and, where necessary, disagreements were resolved by consultation with a third reviewer. In accordance with the protocol, quality assessment of the prospective observational studies was not conducted.

\section{Data synthesis}

Data from the included RCTs were considered to provide primary clinical effectiveness evidence. Data from observational studies and from evidence reviews were considered to provide supporting evidence.

\section{Results}

\section{Literature search and screening}

The process of study selection is shown in Fig. 1. The electronic database searches yielded 2358 papers and six additional references were identified through searches of the other sources. In total, 93 papers reporting on 24 separate studies and reviews were identified. These

Table 1 Inclusion / exclusion criteria

\begin{tabular}{|c|c|c|}
\hline Criteria & Inclusion & Exclusion \\
\hline Patient population & $\begin{array}{l}\text { Adults with progressive, locally advanced or metastatic, } \\
\text { differentiated thyroid carcinoma, refractory to radioactive } \\
\text { iodine }\end{array}$ & Patients with other types of thyroid cancer or diseases \\
\hline Interventions & $\begin{array}{l}\text { Lenvatinib or sorafenib monotherapy (or in combination } \\
\text { with best supportive care) }\end{array}$ & Lenvatinib or sorafenib in combination with other agents \\
\hline Comparators $^{\mathrm{a}}$ & $\begin{array}{l}\text { Lenvatinib or sorafenib monotherapy (or in combination } \\
\text { with best supportive care), best supportive care, placebo }\end{array}$ & $\begin{array}{l}\text { A comparator other than lenvatinib, sorafenib, best } \\
\text { supportive care, placebo }\end{array}$ \\
\hline Outcomes & $\begin{array}{l}\text { The outcome measures to be considered include: overall } \\
\text { survival, progression-free survival, response rate, adverse } \\
\text { effects of treatment, health-related quality of life }\end{array}$ & No study was excluded based on outcomes \\
\hline Study design & $\begin{array}{l}\text { Randomized controlled trials, systematic reviews, } \\
\text { prospective observational studies }\end{array}$ & $\begin{array}{l}\text { Retrospective cohort studies, case series, case reports, } \\
\text { comments, letters, editorials, in vitro, animal, genetic or } \\
\text { histochemical studies }\end{array}$ \\
\hline
\end{tabular}

\footnotetext{
Where studies included a comparator arm
}

${ }^{\mathrm{b}}$ At the inclusion stage, published reports of indirect comparisons were also included if the indirect comparison was based on RCT evidence, even if the conduct of a systematic review was not reported alongside the indirect comparison 


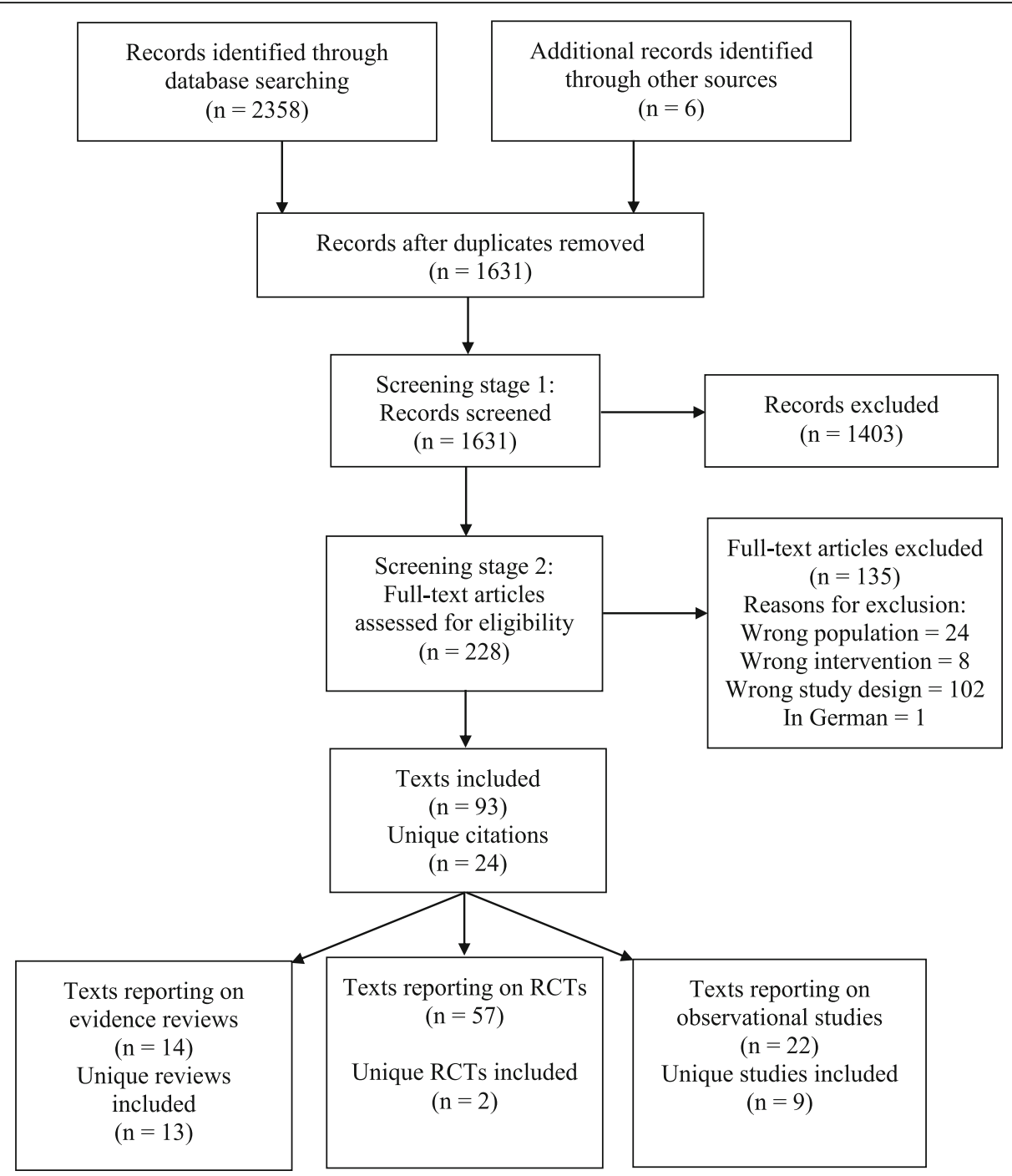

Fig. 1 PRISMA flow diagram: studies included in systematic review

included two RCTs [the SELECT trial [26] and DECISION trial [27]], nine prospective observational studies [28-36] and 13 evidence reviews [24, 25, 37-47].

For the RCTs, in addition to the primary published papers [26, 27], data were extracted from other sources identified from the searches, as appropriate. In this paper, additional information for the SELECT trial was extracted from the company submission from Eisai Ltd. [24], the clinical study report (CSR) (unpublished), three conference abstracts [48-50] and the European public assessment report (EPAR) for lenvatinib [51]. For the DECISION trial, additional information was extracted from the company submission from Bayer HealthCare [25], an additional published paper with supplementary safety data [52], the CSR (unpublished), three conference abstracts [53-55] and the EPAR for sorafenib [56].
For one of the included prospective observational studies of sorafenib, known as UPCC-03305 [32], the majority of data were extracted from later conference reports of the same study [57-59] which reported baseline characteristics from a greater number of patients [58], efficacy data [59] and safety data [57].

\section{Characteristics of included studies Characteristics of randomized controlled trials (primary evidence)}

Both of the included RCTs $[26,27]$ were phase III multicentre double-blind trials designed to compare the intervention of interest (lenvatinib or sorafenib) with placebo. Subjects were randomized 2:1 to the intervention and comparator arms of the SELECT trial (lenvatinib, $n=$ 261; placebo, $n=131$ ) [26] and $1: 1$ in the DECISION 
trial (sorafenib, $n=207$; placebo, $n=210$ ) [27]. Both trials permitted some concomitant therapies (such as TSH suppression) in both the intervention and placebo arms. Thus, the placebo arm in both trials could be considered to be equivalent to BSC. The types of concomitant therapies were broadly similar in both trials. However, a potentially important difference between the two trials was that palliative radiotherapy, which is commonly available as part of BSC in clinical practice, was only permitted in the DECISION trial, not the SELECT trial. Nonetheless, rates of palliative radiotherapy administered to patients in the DECISION trial were relatively low: $10.6 \%$ of patients treated with sorafenib and $21.4 \%$ of patients treated with placebo [25].

Patients were eligible to receive treatment (intervention or placebo) in both the SELECT and DECISION trials until disease progression [26, 27]. In both trials, patients were then enrolled into open extension phases [24, 25]. In the DECISION trial, patients who had progressed on sorafenib were permitted to continue to receive sorafenib until further disease progression and approximately a quarter (26.6\%) of patients did so $[53,54]$. In both the SELECT and DECISION trials, patients in the placebo arms could cross over from the placebo arm to the active treatment arm. Patient crossover on disease progression was high in both trials (SELECT: $87.8 \%$, DECISION: $75 \%)[24,25]$. In addition, in both trials, patients in either arm were also eligible to receive subsequent anti-cancer treatments that were not part of the trial protocols $[24,25]$. In the SELECT trial, at the primary data-cut, $15.7 \%$ of patients randomized to lenvatinib and $12.2 \%$ of patients randomized to placebo, had received subsequent treatment (data from CSR) including treatment with another TKI (data from CSR). Of those who received subsequent treatment, $17.1 \%$ of patients in the lenvatinib arm received pazopanib and $14.6 \%$ received sorafenib (data from CSR). In the placebo arm, the respective proportions were 18.8 and $12.5 \%$ (data from CSR). In the DECISION trial, at the primary data-cut, $20.3 \%$ of patients randomized to sorafenib and $8.6 \%$ of patients randomized to placebo received subsequent treatments [27]. Information on the specific agents used during the DECISION trial follow-up period was not collected.

The median duration of follow-up at the primary datacut was approximately 17 months in both trials [26, 27]. OS results were also reported at a second and third data-cut in both trials [24, 25]. At the third data-cut, the median length of follow-up was approximately 38 months in the SELECT trial [24] and 36 months in the sorafenib arm of the DECISION trial [25] (length of follow-up data have only been reported for the sorafenib arm of this trial).
The OS results from both trials were adjusted for treatment crossover using the Rank Preserving Structural Failure Time Model (RPSFTM) [60]. No adjustments were made, in either trial, to take into account subsequent anti-cancer treatment, as there is no recognised approach for making such adjustments.

A key difference in eligibility between the two RCTs was that the SELECT trial permitted the enrolment of patients who had been previously treated with a TKI (including sorafenib) [26], whilst patients recruited to the DECISION trial were all TKI naïve [27]. Overall, 25.3\% of patients in the lenvatinib arm and $20.6 \%$ of patients in the placebo arm of the SELECT trial had received prior treatment with a TKI [26]. Approximately three quarters of patients who received a TKI in the SELECT trial had previously been treated with sorafenib $(77.2 \%$ in the lenvatinib arm and $77.8 \%$ in the placebo arm) [26].

\section{Characteristics of prospective observational studies and evidence reviews (supporting evidence)}

All nine of the prospective observational studies were single arm studies and included patients whose disease was described as being radioactive iodine refractory $[28-30,33,35,36]$, resistant to radioactive iodine [31, 32] or who may have received multiple treatments of radioactive iodine [34]. Two studies [29, 36] investigated the efficacy and safety of lenvatinib and seven studies considered the efficacy of sorafenib [28, 30-35]; one study included no safety data [34].

Most of the observational studies were conducted in single countries (and often in single centres) in Europe $[28,31,34,35]$, the US [33, 58], and Asia [30, 36]. However, there was one multi-centre international study of lenvatinib (Study 201) [29]. Where reported, patients were recruited prior to the commencement of the SELECT [26] and DECISION [27] trials, the exception was a Japanese study of lenvatinib (Study 208) [36] that began after recruitment to the SELECT trial had ended.

The median length of follow-up, as reported in the EPAR for lenvatinib [56], was longer in the observational studies of lenvatinib $[29,36]$ than in the SELECT trial [24]: 40 months in Study 208 [56] and 51.6 months in Study 201 [56]. Conversely, where reported [28, 34, 35], the median length of follow-up in the observational studies of sorafenib was shorter for OS but longer for other outcomes than in the DECISION trial [25]: 19 months [34] to 25 months [35].

The number of patients included in the nine prospective observational studies varied from nine [30] to 58 [29]. In total, across all studies, 109 patients were treated with lenvatinib, of whom 83 had RR-DTC; 213 patients were treated with sorafenib, of whom 186 had RR-DTC. Other patients included in four of the studies $[28,33$, 36 , 58] had anaplastic $(n=26)$ or medullary $(n=27)$ 
carcinoma. Participant characteristics were reported for all treated patients in each study and, where reported, median age ranged from 55 years [28] to 64 years [33]. Where reported, four studies included a majority of males [28, 29, $33,35]$ and three studies included a majority of females $[31,34,58]$. Only two studies explicitly stated that patients could have received a prior TKI $[29,34]$ and, in these studies, the proportion of patients who did receive a prior TKI ranged from $11.8 \%$ [34] to $29.3 \%$ [29].

Overall, 11 evidence reviews included evidence for lenvatinib and sorafenib [24, 25, 37-43, 46, 47]. Two reviews only included observational studies of sorafenib $[44,45]$.

The earliest review, which presented evidence narratively, was published in 2013 [37] and the most recent reviews (from 2017) were the evidence submissions from the sponsors of lenvatinib [24] and sorafenib [25]. Both of the evidence submissions $[24,25]$ included modified versions of the indirect comparisons of lenvatinib versus sorafenib originally conducted by Tremblay et al. 2016 [46]; the original results [46] were also reported in the Canadian Agency for Drugs and Technologies in Health (CADTH) submission for lenvatinib [39]. One other publication [42], included an indirect comparison of lenvatinib versus sorafenib. The two reviews that included only observational studies of sorafenib meta-analyzed the data from the studies they included $[44,45]$.

\section{Quality assessment of included studies}

Overall, the risk of bias was considered to be low in both RCTs (Additional file 2: Online Resource 2). The quality of nine of the evidence reviews [24, 25, 37-39, 42-45] was considered to be good (Additional file 3: Online Resource 3).

\section{Results from the included studies Primary evidence efficacy evidence}

We have reported RCT evidence from the primary datacuts of the SELECT and DECISION trials $[26,27]$, with the exception of OS data, which are reported for the third data-cut $[24,25]$. The results for OS, PFS and ORR from the RCTs are summarized in Table 2.

For OS, no statistically significant differences between trial arms were found in either trial $[24,25]$. When OS results from both trials were adjusted for treatment crossover, the difference was reported to be statistically significant in the SELECT trial, favouring lenvatinib over placebo [24] but a similar finding was not reported in the DECISION trial for sorafenib versus placebo [25]. Compared to placebo, median PFS and ORR were improved with lenvatinib in the SELECT trial [26] and with sorafenib in the DECISION trial [27]. The difference in ORR between trial arms was particularly pronounced in the SELECT trial, difference in ORR 63.2\% (95\% CI: 57.1
Table 2 Summary of efficacy findings from the SELECT and DECISION trials

\begin{tabular}{|c|c|c|c|c|}
\hline \multirow[t]{2}{*}{ Outcome } & \multicolumn{2}{|l|}{ SELECT trial } & \multicolumn{2}{|c|}{ DECISION trial } \\
\hline & $\begin{array}{l}\text { Lenvatinib } \\
N=261\end{array}$ & $\begin{array}{l}\text { Placebo } \\
N=131\end{array}$ & $\begin{array}{l}\text { Sorafenib } \\
N=207\end{array}$ & $\begin{array}{l}\text { Placebo } \\
N=210\end{array}$ \\
\hline \multicolumn{5}{|l|}{$\mathrm{OS}^{\mathrm{a}}$} \\
\hline Median, months & 41.6 & 34.5 & 39.4 & 42.8 \\
\hline$(95 \% \mathrm{Cl})$ & (31.2-NE) & (21.7-NE) & $(32.7-51.4)$ & $(34.7-52.6)$ \\
\hline Unadjusted HR (95\% CI) & \multicolumn{2}{|c|}{$0.84(0.62-1.13)$} & \multicolumn{2}{|c|}{$0.92(0.71-1.21)$} \\
\hline RPSFTM adjusted OS HR & \multicolumn{2}{|l|}{0.54} & \multicolumn{2}{|l|}{0.77} \\
\hline$(95 \% \mathrm{Cl})^{\mathrm{b}}$ & \multicolumn{2}{|l|}{$(0.36-0.80)$} & \multicolumn{2}{|l|}{$(0.42-1.79)$} \\
\hline \multicolumn{5}{|l|}{$\mathrm{PFS}^{\mathrm{c}}$} \\
\hline Median, months & 18.3 & 3.6 & 10.8 & 5.8 \\
\hline$(95 \% \mathrm{Cl})$ & (15.1-NE) & $(2.2-3.7)$ & (Cls NR) & (Cls NR) \\
\hline Stratified HR (95\% Cl) & \multicolumn{2}{|c|}{$0.21(0.14-0.31)$} & \multicolumn{2}{|c|}{$0.59(0.45-0.76)$} \\
\hline \multicolumn{5}{|l|}{ Objective tumour response } \\
\hline rate $^{c, d}(\%)$ & 64.8 & 1.5 & 12.2 & 0.5 \\
\hline$(95 \% \mathrm{Cl})$ & $(59-70.5)$ & $(0-3.6)$ & $(8-17.7)$ & $(0-2.7)$ \\
\hline Odds Ratio (95\% Cl) & \multicolumn{2}{|c|}{$28.87(12.46-66.86)$} & \multicolumn{2}{|l|}{ NR } \\
\hline$P$ value & \multicolumn{2}{|l|}{$p<0.0001$} & \multicolumn{2}{|l|}{$p<0.0001$} \\
\hline
\end{tabular}

CI Confidence interval, HR Hazard ratio, IPE Iterative Parameter Estimation, NE Not estimable, NR Not reported, OS Overall survival, PFS Progression-free survival, RPSFTM Rank Preserving Structural Failure Time Model

${ }^{\text {a }}$ Data from final data-cut

bBootstrapping Cls

'Assessed by blinded independent review at primary data-cut

dUnlike the SELECT trial, patients who were unevaluable for response were excluded from the analyses in the DECISION trial. There were 18 (4.3\%) patients who were excluded from the objective tumour response analyses in the DECISION trial, 9 (4.3\%) patients in each arm [27]

Source: [26, 27] with additional OS data from Eisai Ltd. 2017 [24] and Bayer HealthCare 2017 [25] and additional ORR data (95\% Cls) from European public assessment report (EPAR) for lenvatinib [51] and EPAR for sorafenib [56]

to 69.4\%) [26]; the difference in ORR in the DECISION trial was $11.7 \%$ (95\% CI: 7.0 to $16.5 \%$ ). Differences between arms were reported to be statistically significant for PFS and ORR in both trials [26, 27].

As some patients in the SELECT trial had previously received a TKI (including sorafenib), subgroup analyses were conducted to assess the effect of this previous treatment and the results have been reported for median PFS and ORR [26]. Median PFS was longer for patients treated with lenvatinib compared with placebo, irrespective of whether patients had received a TKI [26]. Median PFS for those previously treated was 15.1 versus 3.1 months (HR 0.22, 95\% \% confidence interval [CI]: 0.12 to 0.41 ) and for TKI-naïve patients median PFS was 18.7 versus 3.6 months (HR 0.20 , 95\% CI CI: 0.14 to 0.27 ) [26]. Similarly, ORR was improved for patients treated with lenvatinib whether or not they had been previously treated with a TKI $(62.1 \%$ versus $3.7 \%$; odds ratio [OR] 15.57, $95 \%$ CI: 4.06 to 59.72$)$, or not $(65.6 \%$ versus $1.0 \%$; OR 58.88, 95\% CI: 18.95 to 182.91 ) [26]. 


\section{Indirect comparison of lenvatinib versus sorafenib}

In the absence of direct clinical trial evidence comparing treatment with lenvatinib versus treatment with sorafenib, we assessed the feasibility of conducting an indirect comparison to obtain estimates of the relative efficacy and safety of these two treatments. As both the SELECT and DECISION trials shared a common comparator (placebo), it is possible to construct a network. Indeed, indirect comparisons have been reported in evidence reviews $[24,25,39,42,46]$. For an indirect comparison to be reliable: (i) trial and participant characteristics must be sufficiently similar (ii) survival hazard profiles for the shared comparator should be similar and (iii) within trials, hazards should be proportional (since Cox proportional hazard $[\mathrm{PH}]$ modelling [61] was used to generate OS, RPSFTM-adjusted OS and PFS hazard ratios [HRs]). We therefore tested whether all these assumptions were supported by the data.

In relation to (i), we found that there were a number of differences in trial and participant characteristics, which were most pronounced when comparing the placebo arms of the two trials, as highlighted in Table 3. In relation to (ii), from an examination of PFS data, it was also evident that the survival risk profiles of the shared comparator (the placebo arms) were not comparable (Fig. 2). In relation to (iii), we tested the validity of the proportional hazards assumption for OS, RPSFTMadjusted OS and PFS against a non-linear (quadratic) counterfactual using an analysis of variance (ANOVA) test. With the exception of unadjusted OS data in the DECISION trial, we found the PH assumption was violated and thus the network of evidence was compromised for all efficacy outcomes. Therefore, we did not undertake an indirect comparison to compare the efficacy of lenvatinib versus sorafenib.

\section{Supporting efficacy evidence}

Efficacy findings from the observational studies [28-31, 33-36, 59], and meta-analyses conducted by the authors of two sorafenib reviews $[44,45]$ are summarised in Table 4. Data were also extracted from the EPAR for sorafenib [56] for OS and ORR for one of the observational studies [33] and for ORR for another observational study [28]. This is because these results were not presented only for patients with RR-DTC in the published papers of these studies.

Median OS reported in both observational studies of lenvatinib [29, 36] was approximately 32 months, lower than the median OS estimates reported for both arms of the SELECT trial (lenvatinib: 41.6 months, placebo: 34.5 months) [24]. Similarly, median OS reported in three studies of sorafenib [33, 35, 59], which ranged from 23 months [33] to 34.5 months [35], was lower than median OS reported in either arm of the DECISION trial (sorafenib: 39.4 months, placebo: 42.8 months) [25]. Median OS could not be estimated in one other study of sorafenib, as it had not yet been reached [28].

Median PFS and ORR for patients treated with lenvatinib were lower in one study (median PFS: 12.6 months, ORR: 50\%) [29] and higher in another (median PFS: 25.8 months, ORR: 68\%) [36] than reported for patients treated with lenvatinib in the SELECT trial (median PFS: 18.3 months, ORR: 64.8\%) [26]. Median PFS was higher in all four prospective observational studies that reported a median [33-35] as was ORR in all prospective observational studies $[28,30,31,33-35,59]$ than in the DECISION trial [27]; range of median PFS was 12 months [34] to 22.1 months [59] in the observational studies and 10.8 months in the sorafenib arm of the DECISION trial [27], range of ORRs was $15 \%$ [33] to $38.3 \%$ [59] in the observational studies and $12.2 \%$ in the sorafenib arm of the DECISION trial [27]. Reflecting these findings, authors of the sorafenib meta-analyses of single-arm studies [44, 45] reported a higher median PFS and ORR than reported for patients treated with sorafenib in the DECISION trial [27]; median PFS of 17.9 months [45] and ORR of 21 to $22 \%[44,45]$ in the metaanalyses.

Two published papers have reported efficacy results from indirect comparisons of lenvatinib with sorafenib $[42,46]$ utilising data from the SELECT and DECISION trials [26, 27]. There were no statistically significant differences in OS (whether RPSFTM-adjusted, or not) but in both papers, it was reported that PFS was significantly better with lenvatinib versus sorafenib (HR 0.36, 95\% CI: 0.22 to 0.57 ) [42, 46]. The results from a matched adjusted indirect comparison (MAIC) for OS and PFS were very similar to the unmatched results [46]. One of the published papers also included a comparison for ORR and found no statistical significance between lenvatinib and sorafenib (relative benefit 1.72, 95\% CI: 0.15 to 19.40) [42].

\section{Primary safety evidence}

Safety evidence from the SELECT and DECISION trials is summarised in Table 5 . The majority of $\mathrm{AE}$ data for the SELECT trial is taken from the Eisai Ltd. evidence submission [24] as, similar to the reporting in the DECISION trial [27], this reported treatmentemergent AEs, whereas the primary published paper mostly reported treatment-related AEs [26]. Treatment with both lenvatinib and sorafenib led to an increase in the incidence of AEs versus treatment with placebo [24, 27]. Dose interruptions and reductions were very frequent for patients treated with both lenvatinib and sorafenib [26, 27]. Fatal AEs were recorded for $7.7 \%$ of patients treated with lenvatinib and $4.6 \%$ of patients who received placebo in the 
Table 3 Differences in characteristics of the SELECT and DECISION trials (bold text/shaded cells)

\begin{tabular}{|c|c|c|c|c|}
\hline \multirow[t]{2}{*}{ Characteristic } & \multicolumn{2}{|c|}{ SELECT } & \multicolumn{2}{|c|}{ DECISION } \\
\hline & $\begin{array}{l}\text { Lenvatinib } \\
\qquad \mathbf{N}=\mathbf{2 6 1}\end{array}$ & $\begin{array}{c}\text { Placebo } \\
\text { N=131 }\end{array}$ & $\begin{array}{c}\text { Sorafenib } \\
\mathbf{N}=\mathbf{2 0 7}\end{array}$ & $\begin{array}{c}\text { Placebo } \\
\mathbf{N}=\mathbf{2 1 0}\end{array}$ \\
\hline Male, n (\%) & $125(47.9)$ & $75(57.3)$ & $104(50.2)$ & $95(45.2)$ \\
\hline \multicolumn{5}{|l|}{ Ethnicity, n (\%) } \\
\hline White & $208(79.7)$ & 103 (78.6) & $123(59.4)$ & $128(61.0)$ \\
\hline Asian & $46(17.6)$ & $24(18.1)$ & $47(22.7$ & $52(24.8)$ \\
\hline Other & $7(2.7)$ & $4(3.1)$ & $8(3.9)$ & $7(3.4)$ \\
\hline Missing or uncodeable & $\mathrm{n} / \mathrm{a}$ & $\mathrm{n} / \mathrm{a}$ & $29(14.0)$ & $23(11.0)$ \\
\hline \multicolumn{5}{|l|}{ Region, $\mathrm{n}(\%)$} \\
\hline Europe & $131(50.2)$ & $64(48.9)$ & $124(59.9)$ & $125(59.5)$ \\
\hline North America & $77(29.5)$ & $39(29.8)$ & $36(17.4)$ & $36(17.1)$ \\
\hline Other & $53(20.3)$ & $28(21.4)$ & $47(22.7)$ & $49(23.3)$ \\
\hline $\begin{array}{l}\text { Median time from initial } \\
\text { diagnosis, months (range) }\end{array}$ & $\begin{array}{r}66 \\
(0.4-573.6)\end{array}$ & $\begin{array}{r}73.9 \\
(6.0-484.8)\end{array}$ & $\begin{array}{r}66.2 \\
(3.9-362.4)\end{array}$ & $\begin{array}{r}66.9 \\
(6.6-401.8)\end{array}$ \\
\hline ECOG PS $\geq 1, \mathrm{n}(\%)$ & $117(44.8)$ & $63(48.1)$ & $76(36.7)$ & $80(38.1)$ \\
\hline \multicolumn{5}{|l|}{ Histology, $\mathrm{n}(\%)$} \\
\hline Papillary & $132(50.6)$ & $68(51.9)$ & $118(57.0)$ & $119(56.7)$ \\
\hline Poorly differentiated & $28(10.7)$ & $19(14.5)$ & $24(11.6)$ & $16(7.6)$ \\
\hline Follicular, not Hürthle cell & $53(20.3)$ & $22(16.8)$ & $13(6.3)$ & $19(9.0)$ \\
\hline Hürthle cell & $48(18.4)$ & $22(16.8)$ & $37(17.9)$ & $37(17.6)$ \\
\hline Other & 0 & 0 & $2(1.0)$ & $5(2.4)$ \\
\hline Missing or non-diagnosed & 0 & 0 & $13(6.3)$ & $14(6.7)$ \\
\hline \multicolumn{5}{|l|}{ Metastases site, $\mathrm{n}(\%)$} \\
\hline Lung & $226(86.6)$ & $124(94.7)$ & $178(86.0)$ & $181(86.2)$ \\
\hline Lymph node & $138(52.9)$ & $64(48.9)$ & $113(54.6)$ & $101(48.1)$ \\
\hline Bone & $104(39.8)$ & $48(36.6)$ & $57(27.5)$ & $56(26.7)$ \\
\hline Pleura & $46(17.0)$ & $18(13.7)$ & $40(19.3)$ & $24(11.4)$ \\
\hline Head and neck & $\mathrm{NR}$ & NR & $33(15.9)$ & $34(16.2)$ \\
\hline Liver & $43(16.5)$ & $28(21.4)$ & $28(13.5)$ & $30(14.3)$ \\
\hline Prior TKI therapy, n (\%) & $66(25.3)$ & $27(20.6)$ & $\mathrm{n} / \mathrm{a}$ & $\mathrm{n} / \mathrm{a}$ \\
\hline Concurrent radiotherapy, n (\%) & $\mathrm{n} / \mathrm{a}$ & $\mathrm{n} / \mathrm{a}$ & $22(10.6)$ & $45(21.4)$ \\
\hline
\end{tabular}

DTC Differentiated thyroid cancer, ECOG Eastern Cooperative Oncology Group, n/a Not applicable, NR Not reported, PS Performance status, TKI Tyrosine kinase inhibitor

Sources: Eisai Ltd. 2017 [24, 26], EPAR for lenvatinib [27, 51] and appendix to Bayer HealthCare 2017 [25]

Text in bold relates to the most notable differences between placebo arms and shaded cells the most notable differences between trials in any arm 


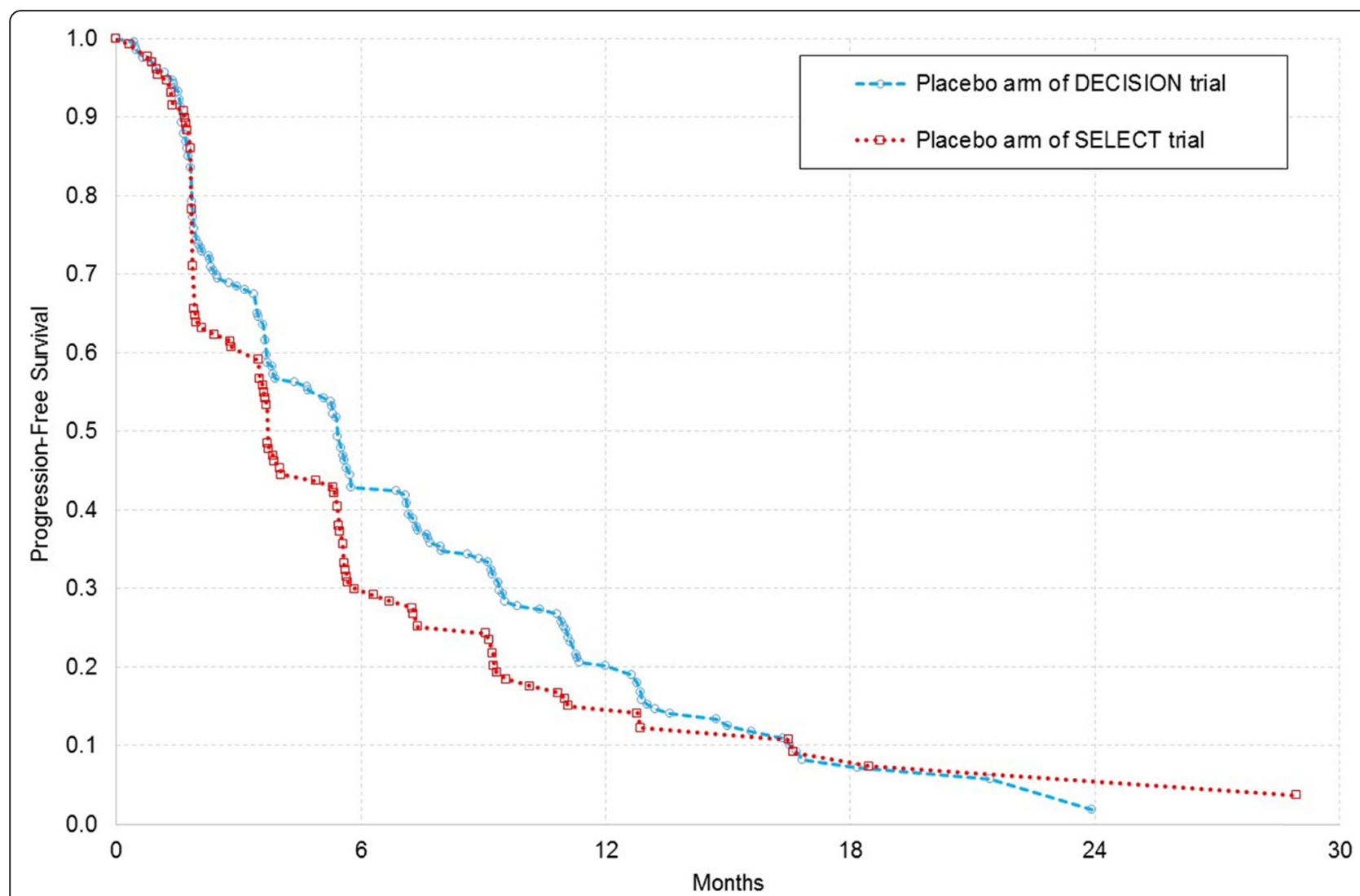

Fig. 2 Comparison of progression-free survival in the placebo arms of the DECISION and SELECT clinical trials. Source: Data provided during the NICE appraisal by Eisai Ltd. and Bayer HealthCare

SELECT trial [26]. Fatal AEs in the DECISION trial were recorded for $5.8 \%$ of patients treated with sorafenib and $2.9 \%$ of patients in the placebo arm [27].

The most frequently reported AEs occurring in around two-thirds of patients were, for lenvatinib, hypertension and diarrhoea [24] and, for sorafenib, hand-foot syndrome, diarrhoea and alopecia [27]. Hypertension was a very frequent Grade $\geq 3 \mathrm{AE}$ reported with lenvatinib [24] and hand-foot syndrome was a frequent Grade $\geq 3 \mathrm{AE}$ reported with sorafenib [27].

Analyses have been undertaken to determine the median time to onset of five AEs for patients treated with lenvatinib in the SELECT trial [48], and eight AEs with for patients treated with sorafenib in the DECISION trial [52]. The results suggest that, when treated with either

Table 4 Summary of efficacy data from observational studies and meta-analyses

\begin{tabular}{|c|c|c|c|c|}
\hline \multirow{2}{*}{$\begin{array}{l}\text { Outcome, } \\
\text { months }\end{array}$} & \multirow{2}{*}{$\begin{array}{l}\text { Lenvatinib } \\
\text { Range from } \\
\text { observational studies }\end{array}$} & \multicolumn{3}{|l|}{ Sorafenib } \\
\hline & & $\begin{array}{l}\text { Range from } \\
\text { observational studies }\end{array}$ & $\begin{array}{l}\text { Estimate from meta-analysis by } \\
\text { Thomas et al. } 2014 \text { [45] }\end{array}$ & $\begin{array}{l}\text { Estimate from meta-analysis } \\
\text { by Shen et al. } 2014 \text { [44] }\end{array}$ \\
\hline OS, median & $31.8-32.3^{[2]}$ & $23-34.5^{[3] a}$ & $-c$ & $-c^{c}$ \\
\hline PFS, median & $12.6-25.8^{[2]}$ & $12-22.1^{[4] \mathrm{b}}$ & 17.9 & $-c^{c}$ \\
\hline $95 \% \mathrm{Cl}$ & & & $17.9-18^{[7]}$ & \\
\hline ORR, \% & $50-68^{[2]}$ & $15-38.3^{[7]}$ & 20.9 & 22 \\
\hline $95 \% \mathrm{Cl}$ & & & $14.3-27.5^{[6]}$ & $15-28^{[7]}$ \\
\hline
\end{tabular}

- = not applicable, Cl Confidence interval, ORR Objective tumour response rate, OS Overall survival, PFS Progression-free survival

${ }^{\mathrm{a}}$ An additional study reported that the median OS had not been met [28]

b One other study reported that the median PFS had not been met [28] and another reported mean PFS only (9.7 months) [30]; in this latter study sorafenib was studied at half the dose of all other studies and included only 9 patients

' No meta-analyses were identified

${ }^{[x]}$ denotes the number of studies from which data are derived 
Table 5 Summary of safety data in the SELECT and DECISION trials

\begin{tabular}{|c|c|c|c|c|}
\hline \multirow[t]{2}{*}{ Outcome, n (\%) } & \multicolumn{2}{|l|}{ SELECT trial } & \multicolumn{2}{|c|}{ DECISION trial } \\
\hline & $\begin{array}{l}\text { Lenvatinib } \\
N=261\end{array}$ & $\begin{array}{l}\text { Placebo } \\
N=131\end{array}$ & $\begin{array}{l}\text { Sorafenib } \\
N=207\end{array}$ & $\begin{array}{l}\text { Placebo } \\
N=209\end{array}$ \\
\hline Any adverse event & $260(99.6)$ & $118(90.1)$ & $204(98.6)$ & $183(87.6)$ \\
\hline Any Grade $\geq 3$ adverse event & $223(85.4)$ & $39(29.8)$ & $133(64.3)$ & $63(30.1)$ \\
\hline \multicolumn{5}{|l|}{ Most common all-Grade AEs ${ }^{a}$} \\
\hline Hypertension & $181(69.3)$ & $19(14.5)$ & $84(40.6)$ & $26(12.4)$ \\
\hline Diarrhoea & $173(66.3)$ & $22(16.8)$ & $142(68.6)$ & $32(15.3)$ \\
\hline Decreased appetite / anorexia & $139(53.3)$ & $24(18.3)$ & $66(31.9)$ & $10(4.8)$ \\
\hline Weight loss & $132(50.6)$ & $19(14.5)$ & $97(46.9)$ & $29(13.9)$ \\
\hline Nausea & $121(46.4)$ & $33(25.2)$ & $43(20.8)$ & $24(11.5)$ \\
\hline Fatigue & $110(42.1)$ & $32(24.4)$ & $103(49.8)$ & $53(25.4)$ \\
\hline Hand-foot syndrome & $84(32.2)$ & $1(0.8)$ & $158(76.3)$ & $20(9.6)$ \\
\hline Rash or desquamation & $48(18.4)$ & $2(1.5)$ & $104(50.2)$ & $24(11.5)$ \\
\hline Alopecia & $32(12.3)$ & $7(5.3)$ & $139(67.1)$ & $16(7.7)$ \\
\hline \multicolumn{5}{|l|}{ Most common Grade $\geq 3$ AEs $^{\mathrm{b}}$} \\
\hline Hypertension & $112(42.9)$ & $5(3.8)$ & $20(9.7)$ & $5(2.4)$ \\
\hline Hand-foot syndrome & $9(3.4)$ & 0 & $42(20.3)$ & 0 \\
\hline Weight loss & $31(11.9)$ & $1(0.8)$ & $12(5.8)$ & $2(1)$ \\
\hline Proteinuria & $26(10)$ & 0 & 0 & 0 \\
\hline \multicolumn{5}{|c|}{ Treatment interruptions, reductions or discontinuations because of an adverse event } \\
\hline Dose interruptions & $215(82.4)$ & $24(18.3)$ & $137(66.2)$ & $54(25.8)$ \\
\hline Dose reductions & $177(67.8)$ & $6(4.6)$ & $133(64.3)$ & $19(9.1)$ \\
\hline Discontinued treatment & $43(16.5)$ & $6(4.6)$ & $39(18.8)$ & $8(3.8)$ \\
\hline
\end{tabular}

a $\geq 40 \%$ in any arm

$\mathrm{b} \geq 10 \%$ in any arm

Source: Eisai Ltd. 2017 [24, 26, 27] and clinical study report for the DECISION trial (unpublished)

lenvatinib or sorafenib, most AEs typically occur early, with a decrease in incidence, prevalence and severity over time $[48,52]$. However, hypertension was a notable $\mathrm{AE}$ omitted from the analysis of lenvatinib data [48].

The incidences of any all-Grade and Grade $\geq 3 \mathrm{AEs}$ for patients treated with lenvatinib were similar in patients who had received a prior TKI to those who had not [49, 50]. The proportion of patients who had at least one lenvatinib dose reduction was also similar between these two subgroups $[49,50]$.

\section{Supporting safety evidence}

The safety data from the prospective observational studies of lenvatinib $[29,36]$, prospective observational studies of sorafenib $[28,33,35,57]$ and meta-analyses of observational studies of sorafenib $[44,45]$ are summarised in Table 6. Prospective observational study authors report either treatment-emergent [28, 29, 35, 36] or treatment-related AEs [33, 57]. The meta-analyses appear to include a combination of treatment-emergent and treatment-related AEs [44, 45].
Although there were differences in the incidences of some AEs across studies [28, 29, 33, 35, 36, 44, 45, 57] and compared to the SELECT and DECISION trials [24, 27], the most common types of AEs with both drugs were similar to those found in the RCTs. As with the RCT evidence [26, 27], dose interruptions and reductions were very frequent for patients treated with either lenvatinib [29] or sorafenib [35, 57].

One of the published reviews [42] compared the relative risk of AEs from treatment with lenvatinib with treatment from sorafenib via an indirect comparison utilising data from the SELECT and DECISION trials [26, 27]. The authors reported that the risk of all-Grade AEs was similar (OR 2.55, 95\% CI: 0.59 to 11.57) [42]. The authors also tested for differences for 17 different types of AEs (treatment-related for lenvatinib and treatment emergent for sorafenib) and found that compared with sorafenib, lenvatinib significantly increased the risk of hypertension (risk ratio [RR] 2.31, 95\% CI: 1.18 to 4.53) but significantly reduced the risk of alopecia (RR 0.33 , 95\% CI: 0.12 to 0.94 ) [42]. There were no significant differences for the other $15 \mathrm{AEs}$, which included the other 
Table 6 Summary of safety data in the observational studies and meta-analyses

\begin{tabular}{|c|c|c|c|c|c|}
\hline \multirow[t]{2}{*}{ Event } & \multirow{2}{*}{$\begin{array}{l}\text { Lenvatinib } \\
\text { TEAEs, } \\
\text { range } \\
\text { from } \\
\text { studies }\end{array}$} & \multirow{2}{*}{$\begin{array}{l}\text { Sorafenib } \\
\text { TEAEs, } \\
\text { range } \\
\text { from } \\
\text { studies }\end{array}$} & \multirow{2}{*}{$\begin{array}{l}\text { Sorafenib } \\
\text { TRAEs, } \\
\text { range } \\
\text { from } \\
\text { studies }\end{array}$} & \multicolumn{2}{|l|}{ Sorafenib AEs } \\
\hline & & & & $\begin{array}{l}\text { Median }(95 \% \text { Cl) from } \\
\text { meta-analysis by } \\
\text { Thomas et al. } 2014^{\text {a }}\end{array}$ & $\begin{array}{l}\text { Median ( } 95 \% \text { Cl) from } \\
\text { meta-analysis by } \\
\text { Shen et al. } 2014\end{array}$ \\
\hline \multicolumn{6}{|c|}{ 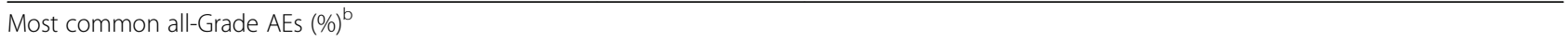 } \\
\hline Hypertension & $76-90^{[2]}$ & $21-42^{[3]}$ & $43^{[2]}$ & $36(27-46)^{[7]}$ & $52(33-72)^{[7]}$ \\
\hline Diarrhoea & $55-67^{[2]}$ & $52-77^{[3]}$ & $75-80^{[2]}$ & $70(62-78)^{[7]}$ & $68(59-77)^{[7]}$ \\
\hline Decreased appetite & $52-78^{[2]}$ & $29^{[1]}$ & $20-82^{[2]}$ & - & - \\
\hline Weight loss & $69^{[1]}$ & $29-58^{[2]}$ & $60-82^{[2]}$ & $57(39-75)^{[7]}$ & $52(33-72)^{[7]}$ \\
\hline Nausea & $50^{[1]}$ & $10-27^{[2]}$ & $30-55^{[2]}$ & - & - \\
\hline Fatigue & $60-73^{[2]}$ & $59^{[1]}$ & $63-66^{[2]}$ & - & - \\
\hline Hand foot syndrome & $22-77^{[2]}$ & $71-79^{[3]}$ & $63-91^{[2]}$ & $74(64-83)^{[7]}$ & $80(68-91)^{[7]}$ \\
\hline Rash & $24^{[1]}$ & $55-88^{[2]}$ & $79-85^{[2]}$ & $67(52-82)^{[7]}$ & $66(50-82)^{[7]}$ \\
\hline Alopecia & $9^{[1]}$ & $52-74^{[2]}$ & $43-79^{[2]}$ & - & - \\
\hline Proteinuria & $61-64^{[2]}$ & - & - & - & - \\
\hline Stomatitis/ mucositis & $31-57^{[2]}$ & $27-48^{[3]}$ & $16-47^{[2]}$ & - & - \\
\hline Cough & $45^{[1]}$ & - & - & - & - \\
\hline Headache & $43^{[1]}$ & $15^{[1]}$ & $16^{[1]}$ & - & - \\
\hline Dysphonia & $43^{[1]}$ & - & - & - & - \\
\hline Infection & - & $68^{[1]}$ & - & - & - \\
\hline Hypocalcaemia & - & $48^{[1]}$ & - & - & - \\
\hline Dry skin & - & - & $84^{[1]}$ & - & - \\
\hline Pruritis & - & - & $77^{[1]}$ & - & - \\
\hline Flatulence & - & - & $70^{[1]}$ & - & - \\
\hline Abdominal/ rectal pain & - & - & $68^{[1]}$ & - & - \\
\hline Arthralgia & - & - & $61^{[1]}$ & - & - \\
\hline \multicolumn{6}{|c|}{ Most common Grade $\geq 3$ AEs $(\%)^{c}$} \\
\hline Hypertension & $10^{[1]}$ & $6-16^{[2]}$ & $4-13^{[2]}$ & $7(3-12)^{[7]}$ & - \\
\hline Hand foot syndrome & $2^{[1]}$ & $23-44^{[2]}$ & $7^{[2]}$ & $19(8-31)^{[7]}$ & - \\
\hline Weight loss & $12^{[1]}$ & $0-10^{[2]}$ & $5-10^{[2]}$ & $5(1.2-9)^{[7]}$ & - \\
\hline Proteinuria & $10^{[1]}$ & - & - & - & - \\
\hline Diarrhoea & $10^{[1]}$ & $3-7^{[2]}$ & $4-7^{[2]}$ & $7(3-10)^{[7]}$ & - \\
\hline Fatigue & $9^{[1]}$ & $9^{[2]}$ & $16^{[1]}$ & $10(4-16)^{[7]}$ & - \\
\hline Stomatitis/ mucositis & $2^{[1]}$ & $9-10^{[2]}$ & $0-2$ & $4(1-7)^{[7]}$ & - \\
\hline Rash & $0^{[1]}$ & $6-16^{[2]}$ & $4-18^{[2]}$ & $7(3-11)^{[7]}$ & - \\
\hline Myocardial infarction & - & $10^{[1]}$ & - & - & - \\
\hline Hand or foot pain & - & - & $12^{[1]}$ & - & - \\
\hline Arthralgia & - & - & $11^{[1]}$ & - & - \\
\hline \multicolumn{6}{|c|}{ Treatment interruptions, reductions or discontinuations because of an adverse event (\%) } \\
\hline Dose interruptions & $74^{[1]}$ & $82^{[1]}$ & - & - & - \\
\hline Dose reductions & $66^{[1]}$ & $42-100^{[2]}$ & $47-55^{[2]}$ & - & - \\
\hline Discontinued treatment & $2-26^{[2]}$ & $23^{[1]}$ & $20^{[1]}$ & - & - \\
\hline
\end{tabular}

- = not reported or not applicable; AE Adverse event, C Confidence interval, TEAE treatment-emergent adverse event; TRAE Treatment-related adverse event ${ }^{a}$ One of the included studies did not include only patients with RR-DTC

${ }^{b} \geq 40 \%$ in any study

c $\geq 10 \%$ in any study

${ }^{[x]}$ denotes the number of studies from which data are derived 
most common AEs reported in the SELECT and DECISION trials $[26,27]$.

The authors of one of the indirect comparisons also presented results for serious AEs (SAEs), serious treatmentrelated AEs and treatment discontinuation due to AEs [42]. The only significant difference was that lenvatinib increased the risk of serious treatment-related AEs compared to sorafenib (RR 4.02, 95\% CI: 1.69 to 9.6) [42].

\section{Evidence for health-related quality of life with treatment}

HRQoL data were only collected during the DECISION trial and the results were presented in a conference abstract [55] and in Bayer HealthCare's evidence submission to NICE [25]. Cancer-specific HRQoL was measured using the Functional Assessment of Cancer Therapy - General (FACT-G) questionnaire [62] and general health status was measured using the generic EuroQol five dimensions, three-level questionnaire (EQ5D-3 L) and the EQ-5D visual analogue scale (VAS) [63]. All questionnaires were self-administered at baseline and day 1 of every 28-day cycle until disease progression [55]. The overall questionnaire completion rate during the DECISION trial was reported to be $>96 \%$ [25].

At baseline, patients' HRQoL data were considered by the authors to be comparable to a normative adult cancer population $[25,55]$. However, at the first assessment (cycle 2, day 1), HRQoL scores (FACT-G, EQ-5D-3 L and VAS) had deteriorated in the sorafenib arm $[25,55]$. Thereafter, the sorafenib arm scores remained similar to the scores recorded at the first assessment until disease progression [25, 55]. Scores for the placebo arm remained very similar to the baseline scores at the first assessment and all subsequent assessments until disease progression $[25,55]$. Results from a mixed linear model showed that, compared with placebo, the FACT-G score was 3.45 points lower in the sorafenib arm than the placebo arm $(p=0.0006)[25,55]$. This is reported to represent a clinically meaningful difference between arms in favour of the placebo arm [25, 55]. While the between arm differences were statistically significant for both EQ-5D-3 L and VAS $(p<0.0001)$, the treatment effects $(-0.07$ and -6.75 , respectively) were reported to be of a small magnitude which did not reach the threshold considered to represent a clinically meaningful difference $[25,55]$.

\section{Discussion}

The aim of this review was to compare the clinical effectiveness evidence for lenvatinib or sorafenib in relation to BSC and also to compare the effectiveness of both drugs with each other.

Trial results show that both drugs are more efficacious in terms of median PFS $[26,27]$ and ORR $[26,27]$ but also result in more AEs than placebo [24, 27]. Placebo can be considered to be a proxy for BSC in both trials, even though concurrent use of palliative radiotherapy was not permitted for patients in the SELECT trial (data from CSR). Some of the most common types of AEs differ by drug, most notably hypertension being very common with lenvatinib [24] and hand-foot syndrome being very common with sorafenib [27]. We were unable to determine the true impact of lenvatinib and sorafenib on OS or how both drugs, particularly lenvatinib, impact upon HRQoL. This is because OS is confounded by treatment crossover in both trials [26, 27] and HRQoL data is limited to reports of sorafenib from the DECISION trial $[25,55]$.

It should however be noted that results for OS (except in the case of the DECISION trial), RPSFTM-adjusted OS and PFS described as statistically significant (or otherwise) should be interpreted with caution, since we found for that for these outcomes, the $\mathrm{PH}$ assumption was violated. It is therefore not possible to ascertain whether the HRs are overestimates or underestimates of the effect of the intervention versus placebo in either trial.

In conducting a feasibility assessment of performing indirect comparisons, we identified potential differences in trial and population characteristics at baseline. Since the PH assumption for OS and PFS data were also found to be violated, we considered that the validity of conducting an indirect comparison (matched or otherwise) using standard methods was questionable. Importantly, we also identified differences in the survival risk profiles of patients in the placebo arms of the trials. These differences may reflect known or unknown differences in trial and participant characteristics. The identification of these differences was our primary reason for considering an indirect comparison to be inappropriate. Of note, the CADTH have also considered the populations to be different, stating that the SELECT trial population had more aggressive disease as reflected by PFS in the placebo arms [39]. Furthermore, in its consideration of the evidence base during the MTA process, the NICE Appraisal Committee agreed that the Kaplan-Meier plots for PFS in the placebo arms of the trials were sufficiently different to suggest there were important differences limiting the robustness of the indirect comparisons [64].

NICE guidance is based on the recommendations of the NICE Appraisal Committee. The extent to which the findings from either of the SELECT and DECISION trials are generalizable to clinical practice was one of the key considerations for the NICE Appraisal Committee [64]. In clinical practice, patients are often not treated with lenvatinib or sorafenib unless their disease is symptomatic, or they have clinically significant progressive disease (e.g. obvious radiological or biochemical progression). Data published in the EPAR for sorafenib [56] 
indicate that approximately $20 \%$ of patients in the DECISION trial had been retrospectively defined as being symptomatic; the equivalent proportion in the SELECT trial was unknown. To be eligible for entry into both trials, patients were required to have had radiographic evidence of disease progression within the last 12 months (SELECT trial) or 14 months (DECISION trial) [26, 27]. Arguably these eligibility criteria suggest that patients had clinically significant disease that was likely to be rapidly progressing, if left untreated. Indeed, clinical opinion presented to the NICE Appraisal Committee was that if patients were not yet symptomatic in the trials, it was likely they would soon become symptomatic [64]. The evidence from both trials, even though it appears to include slightly different trial populations, was, therefore, considered to be generalizable to clinical practice.

In the absence of results from reliable indirect comparisons, findings from observational studies provide important supporting evidence. The magnitude of effects in relation to OS, PFS and the incidence of some AEs differed in prospective observational studies [28-31, 33-36, $57,59]$ and meta-analyses $[44,45]$ to the RCT findings [24-27]. There are a number of reasons that could explain this. First, as with the RCTs, differences in unknown patient characteristics may be contributory factors. Second, the differing lengths of follow-up should be considered. Third, all of the prospective observational studies were relatively small, and so the results are more prone to being influenced by any outlying cases. However, while caution needs to be exercised in comparing results across studies of different study populations, the combined evidence from RCTs [26, 27] and observational studies [28-31, 33-36, 59] suggests ORR may be higher for patients treated with lenvatinib than for patients treated with sorafenib. Evidence from observational studies [28-31, 33, 35, 36, 57] and meta-analyses $[44,45]$ also show that many common AEs reported with lenvatinib and sorafenib in the RCTs $[26,27]$ are also experienced by patients treated with these drugs in other study populations. The evidence shows that some AEs are very common to both lenvatinib and sorafenib (e.g. diarrhoea), whereas other AEs tend to be more drug specific (e.g. hypertension with lenvatinib and hand-foot syndrome with sorafenib) [28, 29, 33, 35, 36, 44, 45, 57]. Therefore, the body of evidence taken as a whole supports the NCCN recommendation that "The decision of whether to use lenvatinib (preferred) or sorafenib should be individualized for each patient based on likelihood of response and comorbidities" [10].

No HRQoL data for lenvatinib are available from either the SELECT trial or the supporting observational studies, $[29,36]$. Only the DECISION trial collected HRQoL data for patients treated with sorafenib, and then only until the end of treatment $[25,55]$. In the
DECISION trial, "mild" reductions in HRQoL were reported for patients treated with sorafenib compared to those receiving the placebo $[25,55]$. Given the different objective tumour response rates and types of AEs reported in the studies of lenvatinib, HRQoL data for patients treated with lenvatinib would have been very informative. It is unclear whether, for patients treated with lenvatinib, obtaining an objective response to treatment is associated with improved HRQoL, or if they too would experience "mild" reductions in HRQoL. The exploration of HRQoL associated with treatment with both drugs is an area requiring further research.

Another area where further research is required relates to the sequential use of lenvatinib and sorafenib. Subgroup analysis results from the SELECT trial suggest that differences in PFS, ORR and AEs for lenvatinib versus placebo were similar regardless of whether a patient had been previously treated with a TKI, or not [26, 49 , 50]. However, no OS evidence has been reported for these subgroups. Furthermore, the number of patients in these subgroups, particularly in the placebo arm, is small. Importantly, there is no evidence for the efficacy or safety of treatment with sorafenib following treatment with lenvatinib.

The evidence presented in our review has been used as the basis for making recommendations for practice in England. Guidance was issued by NICE in August 2018 [64]. In drafting the guidance, the NICE Appraisal Committee considered the uncertainties identified in our review, alongside cost effectiveness evidence, and testimonies from clinical and patient experts. NICE guidance recommends the use of lenvatinib or sorafenib for treating RR-DTC if both drugs are provided at a discounted price [64]. However, NICE guidance also includes the restriction that lenvatinib or sorafenib are only available to patients who have not previously received treatment with a TKI or "if they have had to stop taking a TKI within 3 months of starting it because of toxicity (specifically, toxicity that cannot be managed by dose delay or dose modification)" [64]. The reason given for this restriction is because NICE considered that there is "not enough clinical evidence and no cost-effectiveness evidence to determine whether the treatments are effective when used sequentially" [64]. Restricted use of lenvatinib or sorafenib differs to the licensing [16-19] and also reimbursement approval received elsewhere in the UK [21].

\section{Conclusions}

It is not possible to reliably estimate the relative effectiveness of lenvatinib versus sorafenib for treating RRDTC, but the evidence base clearly demonstrates improvements in PFS and ORR for these treatments when compared with placebo, a proxy for BSC. The 
improvements in PFS and ORR are, however, accompanied by an increased risk of AEs, whilst the effect on patients' OS and HRQoL remains uncertain. Given the slightly different safety profiles of lenvatinib and sorafenib, the evidence from our review supports clinical guideline recommendations that the choice of treatment should consider each patient's circumstances, including their need for a response to treatment and comorbidities.

\section{Supplementary information}

Supplementary information accompanies this paper at https://doi.org/10. 1186/s12885-019-6369-7.

Additional file 1. Online Resource 1. Search strategies for each electronic database used to identify studies.

Additional file 2. Online Resource 2. Risk of bias assessment of the SELECT and DECISION trials.

Additional file 3. Online Resource 3. Quality assessment of systematic review evidence included.

\section{Abbreviations}

AEs: Adverse events; ANOVA: Analysis of variance; ATA: American Thyroid Association; BSC: Best supportive care; CADTH: Canadian Agency for Drugs and Technologies in Health; Cl: Confidence interval; CRD: Centre for Reviews and Dissemination; CSR: Clinical study report; DTC: Differentiated thyroid cancer; EPAR: European public assessment report; EQ-5D VAS: EuroQol five dimensions visual analogue scale; EQ-5D-3 L: EuroQol five dimensions, threelevel questionnaire; EU: European Union; FACT-G: Functional Assessment of Cancer Therapy - General; FTC: Follicular carcinoma; HRQoL: Health-related quality of life; LRiG: Liverpool Reviews and Implementation Group; MTA: Multiple technology appraisal; NCCN: National Comprehensive Cancer Network; NHS: National Health Service; NICE: National Institute for Health and Care Excellence; OR: Odds ratio; ORR: Objective tumour response rate; OS: Overall survival; PFS: Progression-free survival; PH: Proportional hazard; PRISMA: Preferred Reporting Items for Systematic Reviews and MetaAnalyses; PTC: Papillary carcinoma; RCT: Randomized controlled trial; RPSFTM: Rank Preserving Structural Failure Time Model; RR: Risk ratio; RRDTC: Radioactive iodine refractory differentiated thyroid cancer; TKI: Tyrosine kinase inhibitor; TSH: Thyroid stimulating hormone; UK: United Kingdom; US: United States

\section{Acknowledgements}

The authors would like to thank Eleanor Kotas (LRiG) for conducting the literature searches and Juliet Hounsome (LRiG) for assistance with screening.

\section{Authors' contributions}

NF contributed to study selection, data extraction, quality assessment, synthesis and interpretation of the evidence and drafted the manuscript. $\mathrm{RH}$ contributed to study selection and interpretation of the evidence. MC provided statistical advice and quality assessment of the systematic reviews. $S B$ and $A B$ contributed to the interpretation of the evidence. YD and JG contributed to data extraction and quality assessment of the evidence. RD provided critical input at all stages of the review. AS provided clinical advice and interpretation. All authors contributed to the writing of the manuscript and approved the final manuscript.

\section{Funding}

This project was funded by the National Institute for Health Research (NIHR) Health Technology Assessment (HTA) Programme on behalf of the National Institute for Health and Care Excellence (NICE) (project number 16/51/20) [See the HTA programme website for further project information. www.hta. ac.uk]. The funder had no role in the design of the project, data collection, analysis and interpretation, decision to publish or preparation of the manuscript. The views and opinions expressed are those of the authors and not necessarily those of NICE, NIHR, the HTA programme or the Department of Health and Social Care.

\section{Availability of data and materials}

Additional information relating to the search strategies to identify studies and quality assessment of included studies is provided in the supplementary information files (Additional file 1, Additional file 2 and Additional file 3).

\section{Ethics approval and consent to participate}

Not applicable.

\section{Consent for publication}

Not applicable.

\section{Competing interests}

The authors declare that they have no competing interests.

\section{Author details}

${ }^{1}$ Liverpool Reviews \& Implementation Group (LRiG), Department of Health Services Research, Institute of Population Health Sciences, University of Liverpool, Whelan Building, Liverpool L69 3GB, UK. ${ }^{2}$ The Clatterbridge Cancer Centre NHS Foundation Trust, Bebington, Wirral, UK.

Received: 10 January 2019 Accepted: 18 November 2019 Published online: 12 December 2019

\section{References}

1. Cancer Research UK. Thyroid cancer incidence statistics www. cancerresearchuk.org/health-professional/cancer-statistics/statistics-bycancer-type/thyroid-cancer/incidence. Acessed 5 May 2017.

2. National Cancer Institute S, Epidemiology, and End Results Program,. Cancer Stat Facts: Thyroid Cancer https://seer.cancer.gov/statfacts/html/thyro.html. Acessed 4 June 2018.

3. Bomeli SR, LeBeau SO, Ferris RL. Evaluation of a thyroid nodule. Otolaryngol Clin N Am. 2010;43(2):229-38.

4. Jonklaas J, Sarlis NJ, Litofsky D, Ain KB, Bigos ST, Brierley JD, Cooper DS, Haugen BR, Ladenson PW, Magner J, et al. Outcomes of patients with differentiated thyroid carcinoma following initial therapy. Thyroid. 2006; 16(12):1229-42.

5. La Vecchia C, Malvezzi M, Bosetti C, Garavello W, Bertuccio P, Levi F, Negri E. Thyroid cancer mortality and incidence: a global overview. Int J Cancer. 2015;136(9):2187-95.

6. Davies L, Welch HG. Increasing incidence of thyroid cancer in the United States, 1973-2002. JAMA. 2006;295(18):2164-7.

7. Haugen BR, Alexander EK, Bible KC, Doherty GM, Mandel SJ, Nikiforov YE, Pacini F, Randolph GW, Sawka AM, Schlumberger M, et al. 2015 American Thyroid Association management guidelines for adult patients with thyroid nodules and differentiated thyroid Cancer: the American Thyroid Association guidelines task force on thyroid nodules and differentiated thyroid Cancer. Thyroid. 2016;26(1):1-133.

8. Pacini F, Castagna MG, Brilli L, Pentheroudakis G. Thyroid cancer: ESMO clinical practice guidelines for diagnosis, treatment and followup. Ann Oncol. 2012;23(Suppl 7):vii110-9.

9. Perros P, Boelaert K, Colley S, Evans C, Evans RM, Gerrard Ba G, Gilbert J, Harrison B, Johnson SJ, Giles TE, et al. Guidelines for the Management of Thyroid Cancer, third edition. Clin Endocrinol. 2014; 81(Suppl 1):1-122.

10. National Comprehensive Cancer Network (NCCN). NCCN Clinical Practice Guidelines in Oncology: Thyroid Carcinoma. Version 1. 2017 http://www. nccn.org/professionals/physician_gls/pdf/thyroid.pdf. Acessed 10 May 2017.

11. Brose MS. In search of a real "targeted" therapy for thyroid cancer. Clin Cancer Res. 2012;18(7):1827-9.

12. Busaidy NL, Cabanillas ME. Differentiated thyroid cancer: Management of patients with radioiodine nonresponsive disease. J Thyroid Res. 2012; 2012(618985). https://doi.org/10.1155/2012/618985.

13. Schlumberger $M$, Challeton C, De Vathaire F, Travagli JP, Gardet P, Lumbroso JD, Francese C, Fontaine F, Ricard M, Parmentier C. Radioactive iodine treatment and external radiotherapy for lung and bone metastases from thyroid carcinoma. J Nucl Med. 1996;37(4): 598-605. 
14. Durante C, Haddy N, Baudin E, Leboulleux S, Hartl D, Travagli JP, Caillou B, Ricard M, Lumbroso JD, De Vathaire F, et al. Long-term outcome of 444 patients with distant metastases from papillary and follicular thyroid carcinoma: benefits and limits of radioiodine therapy. J Clin Endocrinol Metab. 2006;91(8):2892-9.

15. Newbold KL, Flux G, Wadsley J. Radioiodine for high risk and radioiodine refractory thyroid Cancer: current concepts in management. Clin Oncol (R Coll Radiol). 2017;29(5):307-9.

16. Food and Drug Administration. Lenvatinib (Lenvima). Page Last Updated: 02/13/2015 https://wayback.archive-it.org/7993/20170111231641/http:// www.fda.gov/Drugs/InformationOnDrugs/ApprovedDrugs/ucm434347.htm. Acessed 16 May 2017.

17. European Medicines Agency. Product information: 23/03/2017 Lenvima -EMEA/H/C/003727 -WS/1123. Annex I - Summary of product characteristics. First published: 25/06/2015. Last updated: 24/04/2017 http://www.ema. europa.eu/docs/en_GB/document_library/EPAR___Product_Information/ human/003727/WC500188674.pdf. Acessed 10 May 2017.

18. Food and Drug Administration. Sorafenib (Nexavar). Page Last Updated: 10/ 14/2015. https://wayback.archive-it.org/7993/20170111231704/http://www. fda.gov/Drugs/InformationOnDrugs/ApprovedDrugs/ucm376547.htm. Acessed 16 May 2017.

19. European Medicines Agency. Product information: 02/09/2016 Nexavar -EMEA/H/C/000690 -N/38. Annex I - Summary of product characteristics. First published: 21/12/2009. Last updated: 30/09/2016 http://www.ema. europa.eu/docs/en_GB/document_library/EPAR___Product_Information/ human/000690/WC500027704.pdf. Acessed 10 May 2017.

20. Scottish Medicines Consortium sorafenib $200 \mathrm{mg}$ film-coated tablets (Nexavar $\left.{ }^{\circledR}\right)$ SMC No. (1055/15). 05 June 2015 https://www.scottishmedicines. org.uk/files/advice/sorafenib_Nexavar_FINAL_June_2015_for_website.pdf. Acessed 10 May 2018

21. Scottish Medicines Consortium lenvatinib $4 \mathrm{mg}$ and $10 \mathrm{mg}$ hard capsules (Lenvima $\left.{ }^{\circledR}\right)$ SMC No. (1179/16). 09 September 2016 https:// www.scottishmedicines.org.uk/files/advice/lenvatinib_Lenvima_FINAL_ Sept_2016_amended_30.09.16_for_website.pdf. Acessed 17 November 2016.

22. Centre for Reviews and Dissemination. Systematic Reviews: CRD's guidance for undertaking reviews in healthcare. http://www.york.ac. uk/crd/SysRev/!SSL!/WebHelp/SysRev3.htm\#5_5_QUALITY_ASSESSMENT. htm. Acessed 24 Jan 2017

23. Moher D, Liberati A, Tetzlaff J, Altman DG. Preferred reporting items for systematic reviews and meta-analyses: the PRISMA statement. BMJ. 2009; 339:b2535.

24. Eisai Ltd. Multiple technology appraisal [ID1059]. Lenvatinib for treating differentiated thyroid cancer after radioactive iodine. Eisai submission. April 2017 https://www.nice.org.uk/guidance/gid-ta10101/documents/committeepapers. Acessed 30 July 2018.

25. Bayer HealthCare. Multiple technology appraisal. Lenvatinib and sorafenib for treating differentiated thyroid cancer after radioactive iodine. Company submission to NICE. March 2017 https://www.nice.org.uk/guidance/gid-ta1 0101/documents/committee-papers. Acessed 30 July 2018.

26. Schlumberger $M$, Tahara M, Wirth $L$, Robinson B, Brose MS, Elisei $R$, Habra MA, Newbold K, Shah MH, Hoff AO, et al. Lenvatinib versus placebo in radioiodine-refractory thyroid cancer. $N$ Engl J Med. 2015;372(7):621-30.

27. Brose MS, Nutting CM, Jarzab B, Elisei R, Siena $S$, Bastholt $L$, de la Fouchardiere C, Pacini F, Paschke $R$, Shong $Y K$, et al. Sorafenib in radioactive iodinerefractory, locally advanced or metastatic differentiated thyroid cancer: a randomised, double-blind, phase 3 trial. Lancet. 2014;384(9940):319-28.

28. Ahmed M, Barbachano Y, Riddell A, Hickey J, Newbold KL, Viros A Harrington K, Marais R, Nutting CM. Analysis of the efficacy and toxicity of sorafenib in thyroid cancer: a phase II study in a UK based population. Eur J Endocrinol. 2011;165(2):315-22.

29. Cabanillas ME, Schlumberger M, Jarzab B, Martins RG, Pacini F, Robinson B, McCaffrey JC, Shah MH, Bodenner DL, Topliss D, et al. A phase 2 trial of lenvatinib (E7080) in advanced, progressive, radioiodine-refractory, differentiated thyroid cancer: a clinical outcomes and biomarker assessment. Cancer. 2015;121(16):2749-56.

30. Chen L. Sorafenib at a low dose against radioiodinerefractory metastatic papillary thyroid carcinoma in lung. Thyroid. 2011;21:A58.

31. Duntas LH, Vlassopoulou V, Boutsiadis A, Mantzou E, Anapliotou M, Tsatsoulis A. Sorafenib in the treatment of radioiodine refractory thyroid cancer. A multicenter phase II study. Eur Thyroid J. 2011;0(0):102-3.
32. Gupta-Abramson V, Troxel AB, Nellore A, Puttaswamy K, Redlinger M, Ransone K, Mandel SJ, Flaherty KT, Loevner LA, O'Dwyer PJ, et al. Phase II trial of sorafenib in advanced thyroid cancer. J Clin Oncol. 2008;26(29):4714-9.

33. Kloos RT, Ringel MD, Knopp MV, Hall NC, King M, Stevens R, Liang J, Wakely PE Jr, Vasko W, Saji M, et al. Phase II trial of sorafenib in metastatic thyroid cancer. J Clin Oncol. 2009;27(10):1675-84.

34. Marotta V, Sciammarella C, Capasso M, Testori A, Pivonello C, Chiofalo MG, Pivonello R, Pezzullo L, Botti G, Colao A, et al. Preliminary data of VEGF-A and VEGFR-2 polymorphisms as predictive factors of radiological response and clinical outcome in iodine-refractory differentiated thyroid cancer treated with sorafenib. Endocrine. 2016;16:16.

35. Schneider TC, Abdulrahman RM, Corssmit EP, Morreau H, Smit JW, Kapiteijn E. Long-term analysis of the efficacy and tolerability of sorafenib in advanced radio-iodine refractory differentiated thyroid carcinoma: final results of a phase II trial. Eur J Endocrinol. 2012;167(5):643-50.

36. Takahashi S, Kiyota N, Yamazaki T, Chayahara N, Nakano K, Inagaki L, Toda K, Enokida T, Minami H, Imamura $Y$, et al. Phase II study of lenvatinib in patients with differentiated, medullary, and anaplastic thyroid cancer: final analysis results. J Clin Oncol. 2016;34(15 Suppl). https://doi.org/10.1200/JCO. 2016.34.15_suppl.6088.

37. Anderson RT, Linnehan JE, Tongbram V, Keating K, Wirth LJ. Clinical, safety, and economic evidence in radioactive iodine-refractory differentiated thyroid cancer: a systematic literature review. Thyroid. 2013;23(4):392-407.

38. Canadian Agency for Drugs and Technologies in Health. pan-Canadian Oncology Drug Review Final Clinical Guidance Report Sorafenib (Nexavar) for Differentiated Thyroid Cancer https://www.cadth.ca/sites/default/files/ pcodr/pcodr_sorafenib_nexavar_dtc_fn_cgr.pdf. Acessed 16 May 2017.

39. Canadian Agency for Drugs and Technologies in Health. pan-Canadian Oncology Drug Review Final Clinical Guidance Report: Lenvatinib (Lenvima) for Differentiated Thyroid Cancer https://www.cadth.ca/sites/default/files/ pcodr/pcodr_lenvatinib_lenvima_dtc_fn_cgr.pdf. Acessed 16 May 2017.

40. Gruber JJ, Colevas AD. Differentiated thyroid cancer: focus on emerging treatments for radioactive iodine-refractory patients. Oncologist. 2015;20(2):113-26

41. Jean GW, Mani RM, Jaffry A, Khan SA. Toxic effects of Sorafenib in patients with differentiated thyroid carcinoma compared with other cancers. JAMA Oncol. 2016;2(4):529-34.

42. Kawalec P, Malinowska-Lipien I, Brzostek T, Kozka M. Lenvatinib for the treatment of radioiodine-refractory differentiated thyroid carcinoma: a systematic review and indirect comparison with sorafenib. Expert Rev Anticancer Ther. 2016;16(12):1303-9.

43. McFarland DC, Misiukiewicz KJ. Sorafenib in radioactive iodinerefractory well-differentiated metastatic thyroid cancer. Onco Targets Ther. 2014;7:1291-9.

44. Shen CT, Qiu ZL, Luo QY. Sorafenib in the treatment of radioiodinerefractory differentiated thyroid cancer: a meta-analysis. Endocr Relat Cancer. 2014;21(2):253-61.

45. Thomas L, Lai SY, Dong W, Feng L, Dadu R, Regone RM, Cabanillas ME. Sorafenib in metastatic thyroid cancer: a systematic review. Oncologist. 2014:19(3):251-8.

46. Tremblay G, Holbrook T, Milligan G, Pelletier C, Rietscheli P. Matchingadjusted indirect treatment comparison in patients with radioiodinerefractory differentiated thyroid cancer. Comp Eff Res. 2016;6:13-21.

47. Ye X, Zhu Y, Cai J. Relationship between toxicities and clinical benefits of newly approved tyrosine kinase inhibitors in thyroid cancer: a meta-analysis of literature. J Cancer Res Ther. 2015;11(Suppl 2):C185-90.

48. Haddad R, Schlumberger M, Wirth L, Sherman E, Shah MH, Robinson B, Ductus C, Teng A, Gianoukakis A, Sherman SI. Incidence and timing of common adverse events in lenvatinib-treated patients with radioiodinerefractory thyroid cancer from the select trial. Thyroid. 2015;25:A257.

49. Newbold K, Elisei R, Taylor MH, Krzyzanowska M, Shah MH, Hoff AO, Robinson B, Dutcus C, Song J, Hughes B, et al. Efficacy and safety of lenvatinib for the treatment of patients with 131i-refractory differentiated thyroid cancer with and without prior VEGF-targeted therapy. Asia Pac J Clin Oncol. 2015;11:173.

50. Newbold K, Elisei R, Taylor MH, Krzyzanowska MK, Shah MH, Hoff AO, Robinson B, Dutcus C, Song J, Habra MA. Efficacy and safety of lenvatinib for the treatment of patients with 131 I-refractory differentiated thyroid cancer with and without prior VEGF-targeted therapy. J Clin Oncol. 2015;33(15 Suppl):A6013.

51. European Medicines Agency. Assessment report. Lenvima. International non-proprietary name: lenvatinib. Procedure No. EMEA/H/C/003727/ 
0000. Committee for Medicinal Products for Human Use (CHMP). EMA/ 250082/2015. 30. London, 26 March 2015 http://www.ema.europa.eu/ docs/en_GB/document_library/EPAR__Public_assessment_report/ human/003727/WC500188676.pdf. Acessed 10 May 2017.

52. Worden F, Fassnacht M, Shi Y, Hadjieva T, Bonichon F, Gao M, Fugazzola L, Ando Y, Hasegawa Y, Park do J, et al. Safety and tolerability of sorafenib in patients with radioiodine-refractory thyroid cancer. Endocr Relat Cancer. 2015;22(6):877-87.

53. Paschke R, Schlumberger M, Nutting C, Jarzab B, Elisei R, Siena S, Bastholt L, De La Fouchardiere C, Pacini F, Shong YK, et al. Exploratory analysis of outcomes for patients with locally advanced or metastatic radioactive iodine-refractory differentiated thyroid cancer (RAl-rDTC) receiving openlabel sorafenib post-progression on the phase III DECISION trial. Oncol Res Treat. 2015;38:A186.

54. Schlumberger M, Nutting C, Jarzab B, Elisei R, Siena S, Bastholt L, De La Fouchardiere C, Pacini F, Paschke R, Shong YK, et al. Exploratory analysis of outcomes for patients with locally advanced or metastatic radioactive iodinerefractory differentiated thyroid cancer (RAl-rDTC) receiving open-label sorafenib post-progression on the phase III decision trial. Eur Thyroid J. 2014;3:101.

55. Schlumberger M, Jarzab B, Elisei R, Siena S, Bastholt L, De La Fouchardiere C, Pacini F, Paschke R, Worden F, Bockisch A, et al. Phase III randomized, double-blinded, placebocontrolled trial of sorafenib in locally advanced or metastatic patients with radioactive iodine (RAI)-refractory differentiated thyroid cancer (DTC)-exploratory analyses of patient-reported outcomes. Thyroid. 2013;23:A49-50.

56. European Medicines Agency. CHMP extension of indication variation assessment report: Nexavar. Procedure no.: EMEA/H/C/000690/II/0035. Committee for Medicinal Products for Human Use (CHMP). EMA/ CHMP/220738/2014. London, 25 April 2014 http://www.ema.europa. eu/docs/en_GB/document_library/EPAR_-_Assessment_Report_-_ Variation/human/000690/WC500168976.pdf. Acessed 10 May 2017.

57. Terry RD, Keefe SM, Grande CM, Zifchak L, Brose MS. Timing and severity of skin-related adverse events in a phase II trial of sorafenib (BAY43-9006) in patients with advanced thyroid cancer. J Clin Oncol. 2013;31(15 Suppl). https://doi.org/10.1200/jco.2013.1231.1215_suppl.e17009.

58. Brose MS, Troxel AB, Harlacker K, Redlinger M, Chalian AA, Loevner LA, Mandel SJ, O'Dwyer PJ, Keefe SM. Completion of a phase II study of sorafenib for advanced thyroid cancer. Eur J Cancer. 2009;7(Supplement: 22):2-3.

59. Keefe SM, Troxel AB, Rhee S, Puttaswamy K, O'Dwyer PJ, Loevner LA Mandel SJ, Brose MS. Phase II trial of sorafenib in patients with advanced thyroid cancer. J Clin Oncol. 2011;29(15 Suppl):5562.

60. Robins JM, Tsiatis AA. Correcting for non-compliance in randomized trials using rank preserving structural failure time models. Commun Stat Theory Methods. 1991;20(8):2609-31.

61. Cox DR. Regression models and life-tables. J R Stat Soc Ser B. 1972;34(2): 187-220.

62. Webster K, Cella D, Yost K. The functional assessment of chronic illness therapy (FACIT) measurement system: properties, applications, and interpretation. Health Qual Life Outcomes. 2003;1:79.

63. Group TE. The EuroQol Group EuroQol--a new facility for the measurement of health-related quality of life. Health Policy. 1990;16(3):199-208.

64. National Institute for Health and Care Excellence (NICE). Lenvatinib and sorafenib for treating differentiated thyroid cancer after radioactive iodine [ID1059]. Expected publication date: 8 August 2018 https://www.nice.org.uk/ guidance/gid-ta10101/documents/html-content-2. Acessed 16 May 2018.

\section{Publisher's Note}

Springer Nature remains neutral with regard to jurisdictional claims in published maps and institutional affiliations.

Ready to submit your research? Choose BMC and benefit from:
- fast, convenient online submission
- thorough peer review by experienced researchers in your field
- rapid publication on acceptance
- support for research data, including large and complex data types
- gold Open Access which fosters wider collaboration and increased citations
- maximum visibility for your research: over 100M website views per year
At BMC, research is always in progress.
Learn more biomedcentral.com/submissions

